\title{
PRIMENA POSLOVNE INTELIGENCIJE U HOTELIJERSTVU
}

\section{Dušan Borovčanin ${ }^{1}$ Slobodan Čerović1, Miroslav Knežević}

\author{
${ }^{1}$ Faculty for Tourism and \\ Hospitality Management, \\ Singidunum University, \\ Belgrade, Serbia
}

\section{Correspondence:}

Dušan Borovčanin

e-mail:

dborovcanin@singidunum.ac.rs

\begin{abstract}
Rezime:
Globalizacija i neoliberalni pristup u svetskoj ekonomiji potisnuo je privredna društva u sve veću konkurenciju. Sa pojavom interneta i savremenih informacionih tehnologija (IT), promene koje donose zaokret u svakodnevnom poslovanju dešavaju se u sve kraćim razmacima i ostavljaju neotklonjive posledice za one organizacije koje nisu u stanju da ih isprate. Savremene informacione tehnologije dobile su tako široku primenu u poslovanju, pre svega zato što doprinose unapređenju nekih od najosnovnijih ekonomskih principa kao što su produktivnost, ekonomičnost i rentabilnost. U ovom preglednom radu analiziran je koncept aktuelnog fenomena nazvanog Poslovna inteligencija i prezentovane su ideje o širokoj mogućnosti upotrebe ovog koncepta u oblasti hotelske industrije.
\end{abstract}

Ključne reči:

Business Inteligence, Hospitality, BI.

\section{UVOD}

Poslovna inteligencija predstavlja relativno mladu naučno-istraživačku oblast koja intrigira brojne istraživače iz celog sveta. Razlog za to jesu za sada neograničeni izvori upotrebe ovakvih sistema koji se prevashodno baziraju na savremenim informacionim tehnologijama (IT) i koji ne zavise od oblasti rada ili nivoa odlučivanja. Poslovna inteligencija privlači istraživače i iz prirodnih i iz društvenih nauka, a posebno informatičke inženjere. Iz tog razloga, radovi i udžbenici koji su pisani na temu poslovne inteligencije značajno se razlikuju, kako prema predmetu istraživanja, tako i prema samoj oblasti.

Savremene informacione tehnologije zamenile su neke, do tada, tradicionalne alate koji su pomagali radnoj snazi prilikom obavljanja posla. Čak su i pojedina zanimanja nestala pojavom IT koje su zamenile ljudski rad. Međutim, i pored promena koje donose IT, određena pitanja i dalje opstaju i to su pitanja koja menadžeri sebi postavljaju gotovo svakodnevno, kao npr: Da li investirati u nove proizvode i usluge? Da li otvoriti novo tržište? Da li smanjiti radnu snagu ili zaposliti dodatne kadrove? I tako nadalje. Pa ipak, kako lepo grupa autora iz Australije navodi, sva ova, ili pitanja ovakve vrste, zapravo se svode na 2 pitanja: [1]

1. Šta će se desiti u budućnosti?

2. Koja je najbolja odluka koju mogu da donesem sada? 
Kako dalje navode, koliko god mi bili svesni ili ne, veliki broj naših ličnih, svakodnevnih odluka, zapravo u sebi sadrži ova dva pitanja [1]. Primera radi, kada se vozimo na posao biramo najbolji i najbrži put kojim ćemo stići kako bismo izbegli gužvu. U ovom slučaju zapravo se pitamo kolika će biti gužva na svim potencijalnim alternativnim pravcima i koji put treba odabrati ovog momenta. To isto zapravo se pitamo kada razmišljamo, primera radi o politici cena u hotelijerstvu. Mi se zapravo pitamo koliko će, u narednom periodu iznositi ukupna tražnja za našim smeštajnim jedinicama i koliko će ta tražnja biti finansijski sposobna, kako bismo u datom trenutku mogli da formiramo cene i ponudimo ih na tržištu. Čini se da bez obzira na to kakvu odluku na kraju doneli, ili koliko ona bila kompleksna, mi zapravo moramo napraviti neku vrstu predikcije budućeg stanja i u odnosu na tu zamisao zatim delati. Ovi kratki primeri zapravo pružaju najjednostavniju sliku onoga što danas nazivamo Poslovna inteligencija ili na engleskom Business Inteligence (BI).

Poslovna inteligencija i upravljanje velikim brojem podataka tzv. Big Data postalo je izuzetno važno polje interesovanja, kako akademske, tako i stručne javnosti u poslednje dve decenije [2]. Istraživanje jedne od najuticajnijih organizacija koja se bavi finansijama potkrepljuje ove tvrdnje u svom istraživanju u kojem navode da $97 \%$ kompanija koje imaju registrovan prihod veći od 100 miliona američkih dolara godišnje koristi neku vrstu poslovne inteligencije [3] Jones, Sidorova i Isik, primera radi, razlog tome vide u potrebi organizacija da naprave neki logički smisao od narastajućeg broja, brzine i različitosti podataka koje kompanija prikuplja iz internih i eksternih resursa [4]. Stoga ne čudi rezultat istraživanja koji pokazuje da se Poslovna inteligencija u poslednjih nekoliko godina uvek nalazi u prve dve poslovne komponente po važnosti kod senior menadžera [5].

\section{Definisanje poslovne inteligencije}

Nebrojane definicije poslovne inteligencije do sada su našle svoje mesto u akademskim žurnalima. Tako na primer, Moss i Atre pametno konstatuju da Poslovna inteligencija ima mnogo različitih definicija od strane brojnih eksperata iz različitih oblasti [6]. U skladu sa tim svako daje svoju interpretaciju BI. Jedna grupa autora definiše Poslovnu inteligenciju kao menadžerski alat koji pomaže organizacijama da upravljaju i unaprede svoje poslovne informacije kako bi donosile kvalitetnije odluke [7]. Drugi tvrde da je zadatak Poslovne inteligencije da skuplja podatke, informacije i znanje, i da odgovara brže i sa znalačkim pristupom na poslovne događaje u formi odluka [8]. Watson i Wixom dalje navode da je BI kritična u prilagođavanju promenama koje se dešavaju jednako kao i u poboljšavanju poslovnih performansi [9]. Pojedini autori idu čak dalje i Poslovnu inteligenciju svrstavaju kao kritičnu komponentu svih dugoročnih strategija održivog razvoja i uspeha kompanija [10].

Imajući u vidu sve gorenavedeno, smatramo da je za potrebe ovog rada najprihvatljivija i sveobuhvatnija definicija autora koji tvrdi da Poslovna inteligencija predstavlja 1) sistem, koncept, metod, proces i strukturu 2) kontinuiranog, definisanog i organizovanog prikupljanja, čuvanja, procesiranja i pristupa podacima 3) o klijentima, proizvodima, finansijskim indikatorima, poslovnim operacijama itd. 4) za svrhu sticanja tačnih i pravovremenih informacija neophodnih za donošenje tačnih, pravovremenih, strateških, operativnih i taktičkih odluka 5) sa ciljem unapređenja poslovnih performansi [11].

\section{OPRAVDANOST UVOEENJA POSLOVNE INTELIGENCIJE U HOTELIJERSTVO}

Još u doba robne razmene, ljudi su posedovali informacije o proizvodima i uslugama koje nude [12]. Iskustveno se učilo koja se roba bolje prodaje, a koja lošije. Dodatno su izvođeni zaključci o tome kojim danima u koje vreme ljudi najčešće kupuju određenu robu itd. Dakle, ljudi su upravljali i vodili svoje poslovanje koristeći raspoložive informacije koje su uglavnom sistematizovali na bazi iskustva. Stoga, sa pravom možemo reći da Poslovna inteligencija postoji od početka poslovanja [12].

U jednom broju privrednih delatnosti i danas se veliki broj rukovodioca oslanja na svoje iskustvo u radu, više nego na egzaktne podatke. Pojava informacione tehnologije otvorila je nove mogućnosti za brže i lakše upravljanje podacima [13]. Relevantnost podataka na bazi kojih se donose odluke predmet je istraživanja mnogih naučnika, ali se svi nesumnjivo slažu da je 21. vek i pojava interneta unela takve promene u poslovanje, da je količina informacija počela da prevazilazi okvire za racionalno tumačenje i analizu. Iz tog razloga javila se potreba za još naprednijom upotrebom tehnologije kroz ono što danas poznajemo kao Poslovna inteligencija. Interesantan je primer koji količinu informacija i sposobnost obrade informacija $i$ precizno donošenje odluka poredi sa čuvenom Laferovom krivom u ekonomiji, koja govori o fiskalnoj politici države i nemogućnošću trajnog povećavanja poreza. Taj odnos prikazan je na Slici 1 .

Dakle, kao što je i gore navedeno, Poslovna inteligencija kao termin može da se veže i za same početke ljudskog 
poslovanja, ali se danas kada se pominje najčešće misli na obrasce i alate putem kojih informacione tehnologije strukturno upravljaju podacima i informacijama i uobličuju ih u poslovne odluke. Poslovna inteligencija je relativno mlad koncept, model ili pak poslovno rešenje, i stoga još uvek nema primenu u svim industrijama, ali mnogi autori smatraju da će primena poslovne inteligencije u savremenom poslovanju tek uzeti pravi zamah.

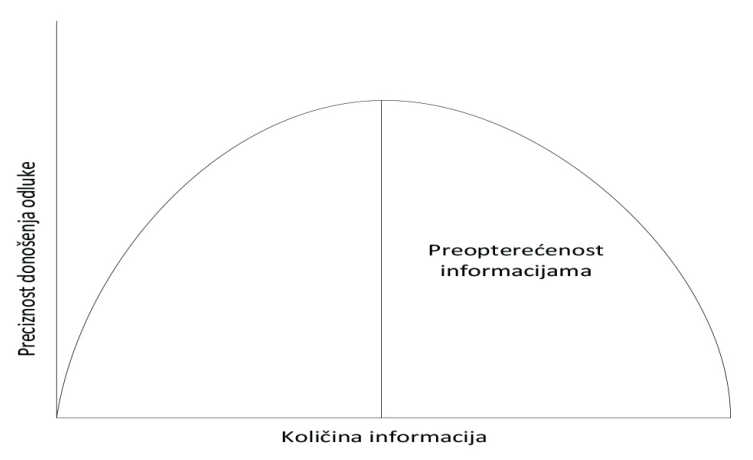

Slika 1. Odnos količine informacija i preciznost u donošenju odluka.

Turizam i hotelijerstvo, koje je posebno u fokusu ovog istraživanja, predstavljaju delatnost koja beleži izuzetno povoljne stope raste na globalnom nivou. Ono što posebno odlikuje ovu industriju to je otpornost na različite vrste kriza, [14], pa se tako sa pravom može očekivati stabilan rast ove delatnosti u narednih nekoliko decenija. Ovakve trendove predviđa i Svetska turistička organizacija u svim svojim scenarijima, pa tako treba očekivati i promene koje će pratiti novine koje dolaze iz drugih industrija. Ovde se pre svega misli na trend uvođenja Poslovne inteligencije u preduzeća iz oblasti marketinga i medija, transporta i logistike, ali i proizvodnih preduzeća itd.

Nesumnjivo je da pojava poslovne inteligencije donosi velike promene u poslovanju, ali upravo iz tog razloga neophodno je pristupiti strateški kada govorimo o implementaciji. Poslovna inteligencija najviše olakšava proces operativnog poslovanja, ali u ovom radu mi želimo da prikažemo da ona predstavlja strateški važnu, novu, funkciju u preduzeću, koja treba biti pažljivo implementirana tako da služi u funkciji generisanja i sprovođenja dugoročne strategije razvoja preduzeća.

U nastavku ćemo dati pregled na koji način poslovna inteligencija može pomoći menadžmentu hotelskih preduzeća prilikom rešavanja određenih složenih problema u poslovanju.

\section{PRIMENA POSLOVNE INTELIGENCIJE U REŠAVANJU KOMPLEKSNIH PROBLEMAU HOTELIJERSTVU}

Kao i mnoge druge delatnosti, i menadžment hotelskih preduzeća odlikuje veliki broj kompleksnih problema. Pa ipak, svaka delatnost obiluje određenim pojedinostima. Kako je u ovom radu od primarnog interesa oblast hotelskog poslovanja, u nastavku ćemo se fokusirati na određene kompleksne probleme koji se pojavljuju u upravljanju savremenim hotelskim preduzećem. Poštujući marketinški pristup u upravljanju hotelom iz marketing miksa pozabavićemo se kompleksnim problemima koji se pojavljuju u promociji, kanalima prodaje i kreiranju cenovne politike u hotelijerstvu.

\section{Problemi u kreiranju politike cena}

Kod razjašnjavanja kompleksnih problema u hotelijerstvu počećemo od kreiranja cenovne politike iz jednostavnog razloga, budući da ovaj proces prethodi promociji i prodaji hotelskog proizvoda, odnosno usluge. Kreiranje cena danas je potpuno drugačije u odnosu na period pre masovne upotrebe informacionih tehnologija. Jedna studija rađena od strane Google-a i Ipsos-a, poznate istraživačke kompanije, ustanovila je da današnji turisti pre svega konsultuju internet kada donose odluku o tome gde i kako će putovati [15]. Upotreba informacionih tehnologija je u značajnoj meri uticala na kanale prodaje sa pojavom interneta i posebno internet distributivnih sistema, ali je samim tim drastično uticala i na politiku kreiranja cena. Cene su danas javno dostupne svim potencijalnim gostima i uporedive sa konkurentskim hotelima na određenoj destinaciji. Iz tog razloga zavladao je pravi rat cena na međunarodnom hotelskom tržištu. U želji da gostima ponude najbolju raspoloživu cenu (Best available rate) hoteli su posegli za izuzetno visokim provizijama koje danas ustupaju internet distributivnim sistemima (IDS). U prilog ovoj tvrdnji govori i izjava Zach Zahrana iz „Kitano Hotela” u Njujorku koji potvrđuje da sigurno $1 / 4$ svih rezervacija širom sveta dolazi od strane internet distributivnih sistema, ali po izuzetno visokoj ceni, odnosno proviziji koja ide do $25 \%{ }^{1}$.

Snaga IDS je upravo u tome što su, s jedne strane hotelima omogućili globalnu prezentaciju, a putnicima lako upoređivanje cene, kvaliteta i iskustava drugih putnika u jako kratkom vremenu, sa druge strane.

1 Videti više na: http://hotelmarketing.com/index.php/content/ article/hotel_websites_might_just_have_the_best_rates_and_ perks\#sthash.2n9iyuRR.dpuf 
Kako kreirati cenovnu politiku u ovakvoj situaciji? Kojom brzinom menjati cene i u odnosu na šta sve se usmeravati u tom procesu? Jedan način jeste sakupljanje velikog broja podataka o cenama koje su do sada objavljivane na internet distributivnim sistemima. Informacioni sistem može skupljati veliki broj podataka o cenama na određenoj destinaciji tokom određenog vremena. Za potrebe dalje analize podataka hotel bi mogao da sakuplja podatke o tome:

1. Koji je datum? (godina, mesec, radni dan, vikend)

2. O kojoj destinaciji je reč?

3. Koliko hotela objavljuje svoje cene na IDS?

4. Kolika je najviša i najniža ponuđena cena na određeni datum?

5. Svakoj pojedinačnoj javno objavljenoj ceni.

Jasno da bi u zavisnosti od veličine skladišta i memorije, kao i brzine samog softvera, zavisilo i koliko bi još dodatno informacija program mogao samostalno da prikuplja, ali će za razjašnjenje principa poslužiti i primer sa 5 promenljivih. Na bazi velikog broja prikupljenih podataka, BI softver bi mogao da vrši predikciju budućih kretanja cena na određenom tržištu. U zavisnosti od dodatnih promenljivih koje bi sistem prikupljao i kombinovanjem podataka, moglo bi se zaključiti da, primera radi, gosti iz Nemačke najčešće borave u hotelu tokom septembra i oktobra meseca i da su u tim periodima spremni da plate višu cenu od prosečne. Ovakva informacija može menadžmentu ukazati da postoji određena aktivnost koja se događa na tržištu, koja uzrokuje veću posetu gostiju iz Nemačke i da u tom slučaju zadrži visoke cene.

Međutim, znamo da prodaja preko internet distributivnih kanala ne čini ukupnu prodaju hotelskih kapaciteta. Možemo li, dakle, i na koji način uz pomoć BI povećati i direktnu prodaju, prodaju korporativnim klijentima? Sigurno je da možemo. Uzmimo za primer da hotel ima potpisanih 100 korporativnih ugovora sa klijentima koji ostvaruju veći broj noćenja tokom godine. U ovom slučaju, najčešće se radi o velikim korporacijama čiji zaposleni nekoliko puta u toku godine, vrlo često iz poslovnih razloga, borave po nekoliko dana u hotelu. BI koji bi obuhvatao i takozvane sisteme za upravljanje imovinom tj. PMS (Property management system) i CRM (Customer relationship management) jednostavno bi mogao da izdvoji najprofitabilnije korporativne klijente. Pa ipak, ne radi se samo o pitanju najprofitabilnijih klijenata. Kombinovanjem podataka možemo utvrditi u kojem periodu dolaze najprofitabilniji gosti i za taj period sačuvati politiku viših cena, s obzirom na to da možemo očekivati određeni nivo garantovano popunjenih kapaciteta. Uz to, ne bismo voleli da naši klijenti primete da je u tom trenutku naša javno istaknuta cena nekoliko procenata niža u odnosu na cenu koju oni plaćaju. Sve ovo su sitnice koje zapravo i čine posao hotelijera izuzetno interesantnim. Uparivanjem individualnih profila gostiju koji dolaze preko korporacija otvora nam i jedan ogroman prostor za personalizovanu promociju, ali će o tome više biti reči u nastavku.

Rešenja za praćenje javno istaknutih cena već postoje, iako smo pokazali da one čine samo jedan segment cenovne politike koju hotelski menadžment treba da kreira. Jasno, BI daleko prevazilazi funkcije prikazane na primeru. Na kraju, treba opet istaći da je cilj ovakvih sistema uvek da pomognu odlučivanju, a nikako da donose odluke umesto rukovodioca.

\section{Problemi u promociji hotelskih preduzeća}

Pretpostavimo da smo uspešno rešili pitanje politike cena u hotelijerstvu, barem u domenu javnih cena koje se objavljuju na IDS kanalima i korporativnih klijenata. Sledeće pitanje koje nam se prirodno nameće jeste: koje ćemo kanale odabrati za promociju našeg hotela? Koje to medije prati naša potencijalna tražnja? Kakva su iskustva starih, redovnih gostiju?

Kreiranje marketing strategije bez prethodnog znanja o tržištu i o tražnji jednako je poslovnom neuspehu. Ipak, količina podataka koju je moguće prikupiti o situaciji na tržištu, trendovima, kao i o samoj tražnji, prevazilazi okvire ljudskih kapaciteta. Iz tog razloga već su kreirani različiti IT sistemi u koje se mogu prikupljati svi gorenavedeni podaci. Tako, primera radi, PMS sadrži (ili može sadržati) gotovo sve podatke i informacije koje su nam korisne kada su u pitanju gosti koji su do sada boravili $\mathrm{u}$ hotelu. Postoje posebna IT rešenja koja danas pomažu $\mathrm{u}$ anketiranju i davanju mišljenja od strane gostiju koji su boravili u hotelu [16]. Uz to, kreirani su i veliki programi za slanje e-mail kampanja, sms kampanja, pa čak i za TV planiranje, iako su u ovom poslednjem slučaju njihovi korisnici najčešće medijske agencije. Međutim, nedostatak svih ovih programa sa aspekta upravljanja je što oni funkcionišu odvojeno, često sa podacima koji se preklapaju i koje zahtevaju ljudski rad u kopiranju podataka i pružaju mogućnost parcijalne analize rezultata poslovanja. Vrlo često dolazi do dupliranja poslovnih operacija, dvostrukog unošenja istih informacija i slično.

Prednost i snaga BI je upravo u tome, u kombinovanom, objedinjenom i strukturiranom unosu i korišćenju, analizi i interpretaciji podataka u vidu poslovnih predloga. Za primer u strategiji targetiranja kod individualnih gostiju može poslužiti kombinacija podataka iz PMS 
sistema i programa kao što je Customer Alliance ${ }^{2}$. Na taj način, na osnovu informacija dobijenih o zadovoljstvu korisnika, kao i o tome koje medije najčešće koristi, možemo lako uputiti ciljanu mejl kampanju, sms kampanju ili kampanju na društvenim ili drugim medijima.

Što se tiče korporativnih gostiju, moguća je integracija individualnih profila gostiju sa korporacijskim profilima. $\mathrm{Na}$ taj način možemo ustanoviti koji su to individualni gosti koji najučestalije dolaze u hotel preko korporativnih ugovora. Ispitivanjem njihovih stavova, takođe preko BI sistema, možemo utvrditi koji su to najzadovoljniji gosti koji su zadovoljni boravkom u našem hotelu. Na ovaj način smo segmentaciju sproveli do samog kraja i sada nam za promociju preostaje samo odabir odgovarajućeg kanala.

\section{Problemi u prodaji}

Karakteristika hotelskog proizvoda je kao i kod svih uslužnih preduzeća specifična i drugačija u odnosu na proizvodna. Nemogućnost skladištenja uslovljava dobro poznavanje discipline koje je poprimila veliku pažnju akademske i stručne javnosti - Revenue Management odnosno upravljanje prihodima. Prvi akademski članak iz ove oblasti objavljen u Cornell Quarterly Journal-u datira još iz 1988. godine [17, 18]. Ipak, teško je reći da se od tada malo toga promenilo u svetu biznisa, ili hotelijerstvu specifično. Najdrastičnija promena svakako dolazi iz IT oblasti, ali je ipak princip umnogome ostao isti. Radi se zapravo o načinu za ostvarivanje najviše moguće ostvarive cene u svakom trenutku. Pritom, treba imati u vidu da se sa pojavom IDS kanala brzina izmene cena dramatično promenila. U današnjem poslovanju hotelske cene se menjaju na dnevnom nivou, vrlo često i nekoliko puta u toku dana. Preduslov jeste dobro poznavanje tržišta i potencijalne traže i njihove finansijske sposobnosti.

Tehnologija je pratila potrebe industrije, pa su tako do sada već razvijeni određeni Revenue management ili Yield Management sistemi i aplikacije. Ipak, neuravnoteženi razvoj potreba za različitim segmentima u poslovanju učinio je da, kao što je već gore napomenuto, svaki od ovih sistema funkcioniše odvojeno, bez mogućnosti kombinovanja podataka, njihovog ukrštanja i pravljenja određenih predikcija.

2 Detaljnije o ovom i sličnom programu i njihovim prednostima videti u radu (Čerović, Knežević, Borovčanin, THE ROLE OF INFORMATION AND COMMUNICATION AND COMMUNICATION TECHNOLOGY IN GUEST SATISFACTION ANALYSIS, 2016)
Pored toga što se većina hotela danas nalazi na više od jednog IDS kanala, hotelski proizvod se prodaje i putem e-maila, telefona, društvenih mreža, tradicionalnih putničkih agencija itd. Integracija svih ovih podataka o pristiglim rezervacijama, njihovoj detaljnoj analizi, kao i o efektima promocije i pogodnostima koje hotel pruža posrednicima u pojedinim slučajevima, zahteva analizu nekoga od zaposlenih po potrebi. Nekada je ta analiza potrebna na nedeljnom, nekada na mesečnom ili godišnjem nivou, ali nedostatak ovakve analize je upravo $\mathrm{u}$ tome što se ona odnosi na prethodni period. To dalje znači da što se ređe radi analiza, zapravo je teže otkloniti posledice eventualnih grešaka koje možemo uočiti ako imamo u vidu da se cene menjaju na dnevnom nivou, kao što je već spomenuto.

BI bi mogao da pruži mogućnost trenutnog uvida u različite kanale prodaje, njihov uspeh, i da na bazi istorijskih rezultata i kombinacijom raspoloživih podataka pravi predikcije. Poznavanje ovog i dalje interesantnog koncepta Revenue Management-a i dobro rukovanje sa savremenim informacionim tehnologijama samo su neka od znanja i veština koja se traže od zaposlenih u savremenom hotelskom preduzeću. Iz tog razloga u narednom poglavlju ćemo se baviti time koja sve znanja, veštine i kompetencije treba da poseduje jedan zaposleni u savremenom hotelskom preduzeću.

\section{ZAKLJUČAK}

Hotelsko poslovanje obiluje podacima, i dalje predstavlja radno intenzivnu delatnost. Poslovna inteligencija trebalo bi da pomogne u obradi tako velike količine podataka i informacija koje prevazilaze ljudske kapacitete. Uz to, trenutni pristup svim mogućim podacima uz njihovo trajno čuvanje i pregled mogućih scenarija jeste nešto što bi trebalo da značajno unapredi proces donošenja odluke. Poslovna inteligencija donosi i novi kvalitet kombinovanja podataka koji na prvi pogled ne moraju da budu direktno povezane. Ovakav način zaključivanja ostavlja prostor za bolje razumevanje poslovnih aktivnosti i pravovremeno reagovanje i donošenje ispravnih odluka.

U samom radu predstavljene su koristi od poslovne inteligencije prilikom rešavanja različite vrste kompleksnih problema koje prevazilaze kapacitete ljudskog uma. Dati su predlozi za implementaciju određenih elemenata iz strategijskog menadžmenta kako bi proces uvođenja poslovne inteligencije bio uspešno i kvalitetno implementiran. Ukazano je na neophodnost usklađivanja strategije organizacije i operativnog poslovanja, kao i na merenje učinaka koji treba da posluže kao polazna osnova prilikom projekcije budućih dešavanja. 


\section{LITERATURA}

[1] Z. Michaelewicz, M. Schmidt, M. Michaelewicz/C. Chiriac, Adaptive Business Inteligence, Adelaide: Springer, 2006.

[2] C. Hsinchun , C. Roger/S. Veda, „Business intelligence and analytics:from big data to big impact" MIS Quarterly, pp. 1165-1188, 2012.

[3] Bloomberg Businessweek, „The Current State of Business Analytics:Where Do We Go From Here?" New York, 2011.

[4] O. Isik, M. Jones/A. Sidorova, „Business intelligence success: The roles of BI capabilities and decision environments, Information \& Management, pp. 1223, 2013.

[5] J. Luftman/T. Ben-Tvi, „Key issues for IT executives 2010: judicious IT investments" MIS Quarterly, p. 263-273, 2010.

[6] L. Moss/S. Atre, Business Intelligence Roadmap: The Complete Project Lifecycle for DecisionSupport Applications, Addison Wesley, 2003.

[7] M. Ghazanfari, M. Jafari/S. Rouhani, „A tool to evaluate the business intelligence of enterprise systems".

[8] G. Bargshadya, F. Alipanaha, A. W. Abdulrazzaqb/F. Chukwunonsoc, „Business Inteligence Technology Implimentation Readiness Factors" Jurnal Teknologi, pp. 7-12, 2014.

[9] H. Watson/H. Wixom, „Enterprise agility and mature BI capabilities" Business Inteligence Journal, pp. 13-27, 2007.
[10] G. Gangadharan/S. Swami, „Business Intelligence Systems: Design and Implementation Strategies" u Information Technology Interfaces IT1 2004, Cavtat, Croatia, 2004.

[11] G. Pranjić, „Influence of business and competitive intelligence on making right business decisions," Ekonomska misao i praksa , pp. 271-288, 2011.

[12] J. Raković, „Singipedia“ 0709 2016. [Na mreži]. Available: www.singipedia.com.

[13] D. Buhalis/P. O'Connor, „Information Communication Technology Revolutionizing Tourism" Tourism Recreation Research, pp. 7-16, 2005.

[14] N. Sekulović, Turizam u uslovim adelovanja kriza, Beograd: Univerzitet Singidunum, 2012.

[15] G. Ipsos MediaCT, „Travel Study“ Google Inc., 2013.

[16] S. Čerović, M. Knežević/D. Borovčanin, „THE ROLE OF INFORMATION AND COMMUNICATION AND COMMUNICATION TECHNOLOGY IN GUEST SATISFACTION ANALYSIS,“ u ICT IN TOURISM \& HOSPITALITY, Belgrade, 2016.

[17] C. Anderson / X. Xie, „Improving hospitality industry sales twenty-five years of revenue management," Cornell Hospitality Quarterly, pp. 52-67, 2010.

[18] O. Lefever, „Boosting Your Bottom Line with Yield Management,"Cornell Hospitality Quarterly, 1988. 